\title{
Spheroidization of molybdenum powder by radio frequency thermal plasma
}

\author{
Xiao-ping Liu ${ }^{1,2)}$, Kuai-she Wang ${ }^{1,2)}$, Ping $\mathrm{Hu}^{1,2)}$, Qiang Chen ${ }^{3)}$, and Alex A. Volinsky ${ }^{4)}$ \\ 1) School of Metallurgical Engineering, Xi'an University of Architecture \& Technology, Xi'an 710055, China \\ 2) Metallurgical Engineering Research Center of Shaanxi Province, Xi'an 710055, China \\ 3) State Technical Center, Jinduicheng Molybdenum Co. Ltd, Xi'an 710068, China \\ 4) Department of Mechanical Engineering, University of South Florida, Tampa FL 33620, USA \\ (Received: 18 September 2014; revised: 27 November 2014; accepted: 1 December 2014)
}

\begin{abstract}
To control the morphology and particle size of dense spherical molybdenum powder prepared by radio frequency (RF) plasma from irregular molybdenum powder as a precursor, plasma process parameters were optimized in this paper. The effects of the carrier gas flow rate and molybdenum powder feeding rate on the shape and size of the final products were studied. The molybdenum powder morphology was examined using high-resolution scanning electron microscopy. The powder phases were analyzed by X-ray diffraction. The tap density and apparent density of the molybdenum powder were investigated using a Hall flow meter and a Scott volumeter. The optimal process parameters for the spherical molybdenum powder preparation are $50 \mathrm{~g} / \mathrm{min}$ powder feeding rate and $0.6 \mathrm{~m}^{3} / \mathrm{h}$ carrier gas rate. In addition, pure spherical molybdenum powder can be obtained from irregular powder, and the tap density is enhanced after plasma processing. The average size is reduced from 72 to $62 \mu \mathrm{m}$, and the tap density is increased from 2.7 to $6.2 \mathrm{~g} / \mathrm{cm}^{3}$. Therefore, RF plasma is a promising method for the preparation of high-density and high-purity spherical powders.
\end{abstract}

Keywords: powder materials; molybdenum; radio frequency plasma; spheroidization; processing parameters

\section{Introduction}

Molybdenum is a refractory metal with high melting and boiling points. Molybdenum alloys exhibit excellent properties, including high hardness and strength, good wear resistance, small thermal expansion coefficient, good corrosion resistance, and excellent thermal shock resistance [1-2]. Because of the good flowability and high apparent density, spherical molybdenum powders are widely used in thermal spraying, welding, contact material preparation, powder metallurgy, powder injection molding, and other fields. In thermal spraying, the resulting coating prepared using spherical molybdenum powders is denser, more uniform, and exhibits better wear resistance. Porous molybdenum material with spherical molybdenum powder and interconnected pores can be used to prepare homogeneous molybdenum-copper alloys. Using spherical molybdenum powder can ensure the uniformity of the molybdenum-copper contact material, prevents the breakdown of local excessive ablation, improves the performance of molybdenum-copper alloy contacts, and extends its service life. In the powder metallurgy process, green compacts prepared from spherical molybdenum powders undergo a uniform and small amount of shrinkage during sintering to obtain an ideal sintered body, which is conducive to subsequent processing. Additionally, in powder injection molding, products made from spherical molybdenum powder also undergo a small shrinkage, and accurate dimensions can be obtained because spherical molybdenum powders exhibit good flowability and high apparent densities.

Spherical molybdenum powder is a type of high-tech material utilized in thermal spraying, powder metallurgy, and other industrial applications because of the unique nature of its preparation technology and excellent properties. This material has attracted the attention of domestic and international markets, resulting in further research and development [3]. Currently, methods such as spray granulation or the rotating electrode method can be used to prepare spherical molybdenum powder. However, these methods have some shortcomings such as the high oxygen content,

Corresponding author: Kuai-she Wang E-mail: wangkshe2826@163.com 
quasi-spherical shape, powder particle adhesion, large particle size, wide particle size distribution, and low preparation efficiency. In China, no adequate research and development of high-performance spherical molybdenum powder with low oxygen content has been performed.

Thermal plasma technology has drawn considerable attention over the last few decades because of its wide range of operating conditions and various industrial applications [4-7]. For instance, thermal plasma technology has been developed to synthesize metals and ceramics [8-14]. Compared with direct current (DC) thermal plasma, radio frequency (RF) thermal plasma produced by an RF electric field without electrodes has particular advantages such as high energy that is environmentally friendly, large volume, and suitability for the synthesis of high-purity materials. RF thermal plasma has been extensively used for the spheroidization of refractory metals, ceramics, and powders [15-18]. It has been successfully utilized to spheroidize tantalum powder and tungsten powder. However, there are few reports on the use of RF plasma to prepare spherical molybdenum powder. In the present paper, irregular molybdenum powder particles that were carried by powder feeding gas into the RF plasma torch, whose temperature is as high as $10000 \mathrm{~K}$, were rapidly heated, melted, and then quenched to form micro-spherical molybdenum powder particles, and the effect of the processing parameters on the final product was also discussed. This method can also be extended to spheroidize and densify other refractory metals or ceramics [19-23].

\section{Experimental}

\subsection{RF thermal plasma setup}

The spheroidization and densification of molybdenum powder was performed in the RF thermal plasma system under atmospheric pressure. A schematic illustration of the setup is presented in Fig. 1. The plasma reactor system consisted of an RF generator (100 kW, $4 \mathrm{MHz})$, plasma generator with a downward plasma torch, power supply unit, cylindrical reactor, precursor feeding system, powder collector, quenching chamber, gas delivery system, and off-gas exhaust system. The plasma torch included three main parts: a four-turn induction coil, cooled by water; an injection probe, also cooled by water; and a confinement tube. The reactor consisted of a $25-\mathrm{cm}$ inner diameter vertical quartz tube that was $200-\mathrm{cm}$ long. The quenching chamber, connected to the bottom of the reactor, was a water-cooled dual layer stainless steel box, which cooled the outgoing gas to less than $200^{\circ} \mathrm{C}$. The precursor feeding system could feed the irregular molybdenum powder precursor with a controlled feeding rate into the plasma flame. The resulting products were collected at the bottom of the chamber.

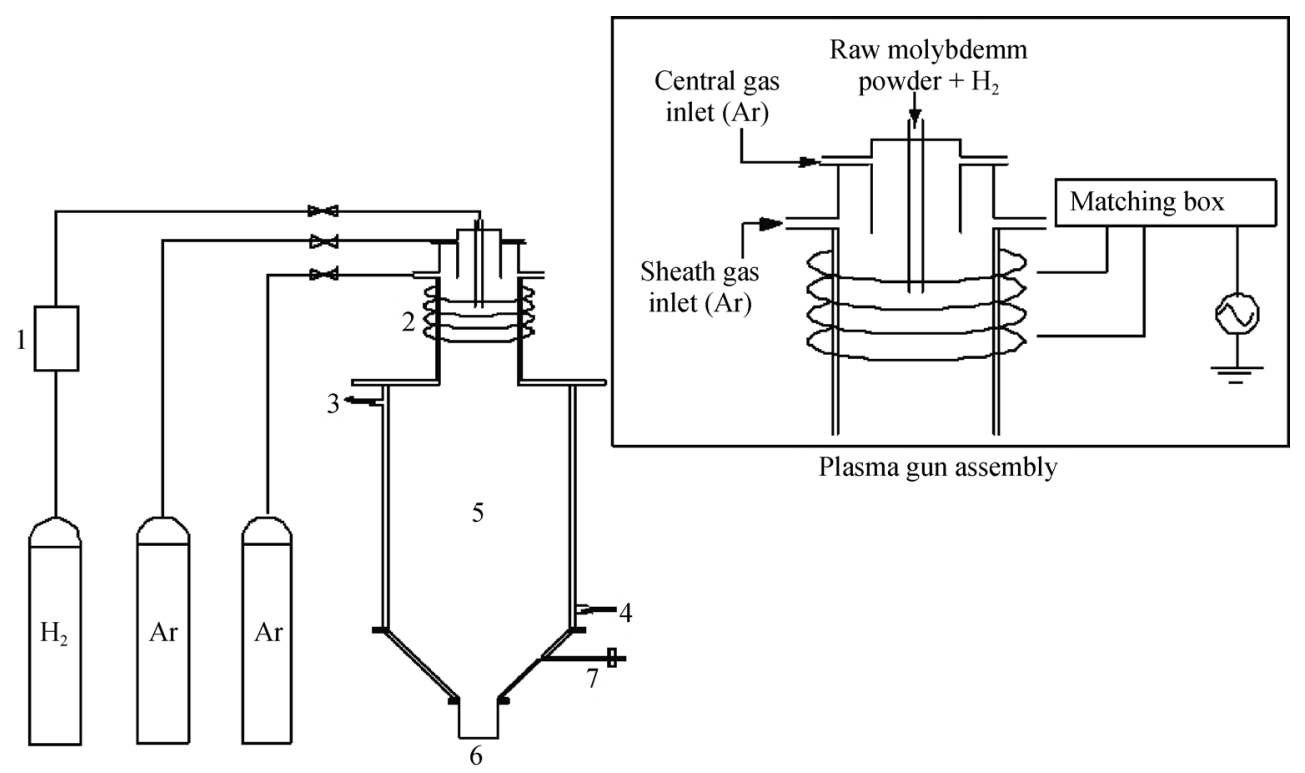

Fig. 1. Schematic diagram of the RF thermal plasma system: 1-entrained-flow powder feeder for raw molybdenum powder; 2-plasma torch; 3-cooling water outlet; 4-cooling water inlet; 5-two-layer water-cooled stainless steel quenching chamber; 6-powder collector; 7-vacuum system.

\subsection{Preparation of spherical molybdenum powders}

Irregular molybdenum powder $(99.9 \%$ pure, -200 to 325 mesh) produced by the Jinduicheng Molybdenum Co. Ltd. was used as the precursor. Argon (Ar, 99.99\% pure) was used as the plasma gas (central gas and sheath gas) and hy- 
drogen $\left(\mathrm{H}_{2}, 99.99 \%\right.$ pure $)$ was used as the carrier gas. Both the argon and hydrogen were provided by the Yatai Gas Company. Before delivering the precursor into the plasma flame, the reactor was heated by the plasma flame for $8 \mathrm{~min}$ until the system temperature reached a steady level. Hydrogen gas flowed through the precursor feeding system to carry the precursor molybdenum powders into the plasma flame. Because the plasma torch had an extremely high temperature, approximately $10000 \mathrm{~K}$, the injected irregular molybdenum powder was rapidly heated, the surfaces of the large particles were melted, and the small particles were completely melted. When these melted particles passed through the quenched chamber, they were condensed under the effect of surface tension and became spherical particles. The spherical molybdenum powders produced were collected at the bottom of the chamber. The reactor was purged with $\mathrm{Ar}$ at a flow rate of $5 \mathrm{~L} / \mathrm{min}$ for $10 \mathrm{~min}$ before and after each experiment. To operate the RF plasma torch in a controlled fashion, the plasma processing parameters are very important and are listed in Table 1.

Table 1. Experimental parameters for spherical Mo powder preparation by the RF plasma

\begin{tabular}{lc}
\hline Center gas flow rate (argon) $/\left(\mathrm{m}^{3} \cdot \mathrm{h}^{-1}\right)$ & 0.6 \\
Sheath gas flow rate (argon) $/\left(\mathrm{m}^{3} \cdot \mathrm{h}^{-1}\right)$ & 0.9 \\
Carrier gas flow rate (hydrogen) $/\left(\mathrm{m}^{3} \cdot \mathrm{h}^{-1}\right)$ & $0.5-1.2$ \\
Powder feed rate / $\left(\mathrm{g} \cdot \mathrm{min}^{-1}\right)$ & $45-90$ \\
Raw molybdenum powder / mesh & -200 to 325 \\
Plasma power / $\mathrm{kW}$ & 30 \\
\hline
\end{tabular}

\subsection{Characterization of the molybdenum powders be-} fore and after spheroidization

The product phases were analyzed using an X-ray diffractometer (XRD, Rigaku D/MAX-2400) with the $2 \theta$ angle ranging from $20^{\circ}$ to $80^{\circ}$ at a scan rate of $0.02^{\circ}$ s operated at $40 \mathrm{kV}$ and $30 \mathrm{~mA}$ with $\mathrm{Cu} \mathrm{K}_{\alpha}$ radiation. Both the raw materials and produced powders were characterized by high-resolution scanning electron microscopy (SEM, JSM-6700F) to determine the particle morphology. The tap density of the molybdenum powder before and after plasma treatment was measured using a Hall flowmeter, and the apparent density was determined using a Scott volumeter. The flowability was investigated using a calibrated funnel (the Hall flowmeter).

\subsection{Statistics of the spheroidization efficiency}

The percentage of spherical particles in the sample after spheroidization was calculated from the SEM images. The particles in each sample were randomly counted 3 times, and the mean percentage was used as the spheroidization efficiency of the sample.

\section{Results and discussion}

\subsection{X-ray diffraction analysis}

Fig. 2 presents the X-ray diffraction patterns of the molybdenum powder after spheroidization. The results reveal that there was no intervention of oxides and other impurities that could be detected during the preparation of the spherical molybdenum powder. The plasma gas did not come into contact with the electrodes, which eliminated additional sources of contamination. Furthermore, hydrogen, as the carrier gas, also provided a reducing atmosphere, which ensured that the final product was high-purity molybdenum metal powder. Studies have shown that plasma treatment can effectively remove impurity elements in molybdenum powder. For example, the content of oxygen was $860 \mathrm{ppm}$ before plasma treatment but decreased to $80 \mathrm{ppm}$ after plasma treatment. The reason for the decrease of the oxygen content was that $\mathrm{H}^{+}$in the plasma atmosphere captured the $[\mathrm{O}]$ in the molybdenum powder. Due to space limitations, this aspect is not elaborated in this article.

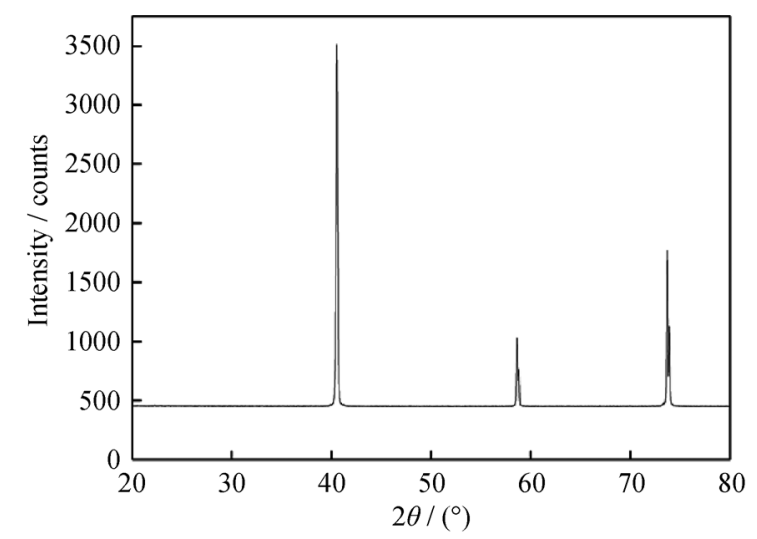

Fig. 2. XRD pattern of the spherical Mo powder after plasma processing.

\subsection{Morphology, particle size, and tap density before and after plasma spheroidization}

Fig. 3 presents high-resolution SEM images of the molybdenum powders before and after plasma spheroidization. The SEM image of the feedstock molybdenum powder with an average particle size of $70 \mu \mathrm{m}$ is shown in Fig. 3(a), presenting aggregates of irregular shape powders. Fig. 3(b) shows typical SEM images of the synthesized molybdenum powders with high sphericity and smooth surface after the RF plasma processing; these powders were obtained under the following conditions: carrier gas flow rate of $0.6 \mathrm{~m}^{3} / \mathrm{h}$ 
and powder feed rate of $50 \mathrm{~g} / \mathrm{min}$. The laser particle size distributions of the molybdenum powders before and after spheroidization are shown in Fig. 4. After spheroidization, the curve of the particle size distribution is narrowed, the powder particle size distribution became more uniform, more than $80 \%$ of the molybdenum powder after spheroidization had the particle size between 44 and $86 \mu \mathrm{m}$, and $d(0.5)$ was $62.220 \mu \mathrm{m}$. Compared with the feedstock molybdenum powder with $d(0.5)$ of $72.243 \mu \mathrm{m}$, the powder size after plas-

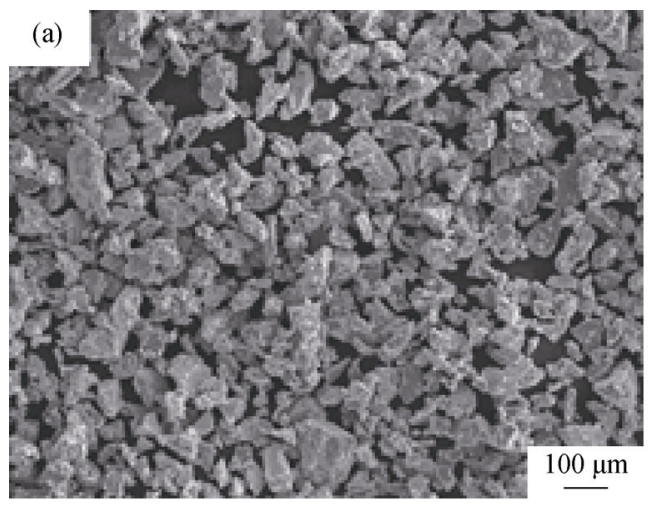

ma treatment was obviously decreased. Plasma processing was also observed to cause powder refinement in addition to spheroidization. There are two reasons for the refinement. First, the feedstock molybdenum powder was made up of porous molybdenum powder with low density or aggregates of many small particles; these aggregates or loose particles would be cracked rapidly and refined. Second, the molybdenum powder went through the gasification-condensation processing, which also caused the refinement.

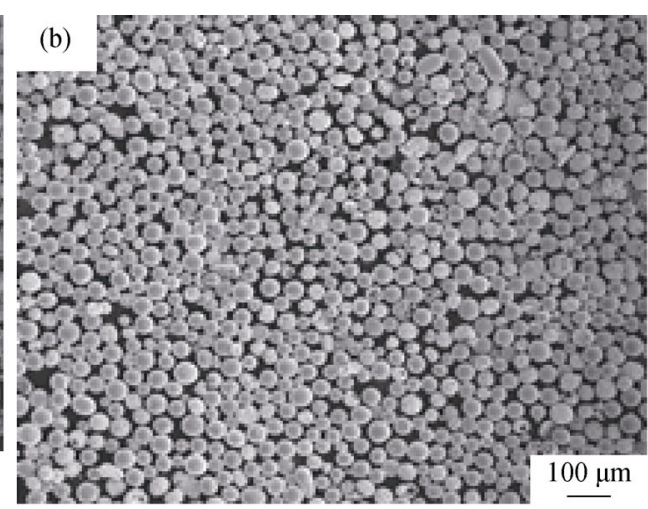

Fig. 3. High-resolution SEM images of the molybdenum powders: (a) before spheroidization and (b) after spheroidization.
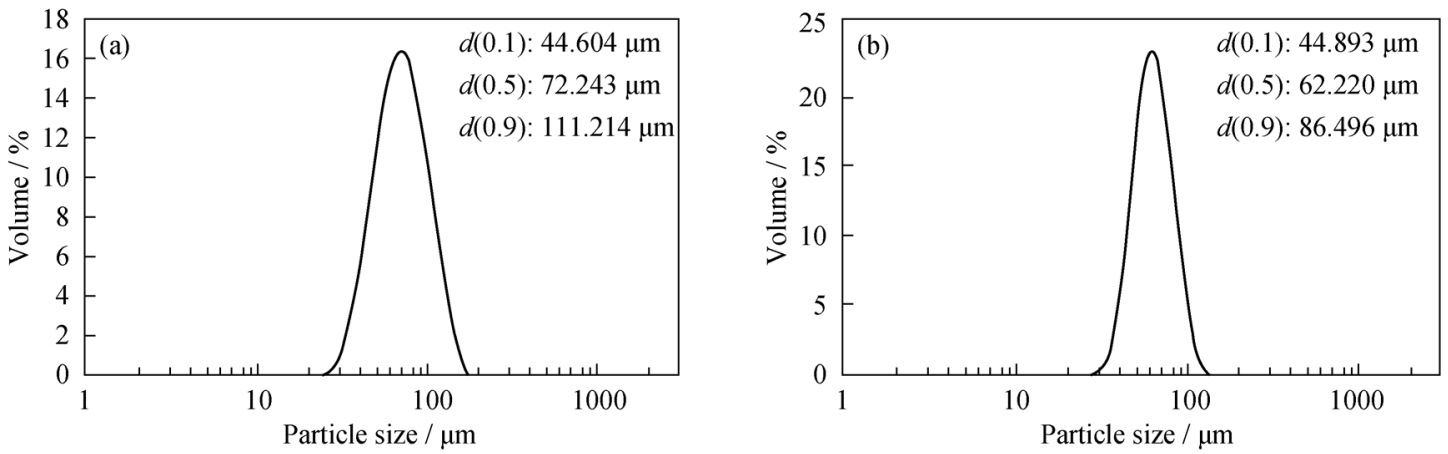

Fig. 4. Particle size distribution of the molybdenum powders in Fig. 3: (a) before spheroidization and (b) after spheroidization.

The tap densities of the molybdenum powder before and after plasma treatment in Fig. 3 were determined to be 2.7 and $6.2 \mathrm{~g} / \mathrm{cm}^{3}$, respectively, using a Hall flowmeter. The tap density of the molybdenum powder after spheroidization was greater than that of the raw molybdenum powder. The fact that the molybdenum powder in this study has a large tap density is related to its sphericity. A higher spherical efficiency results in a larger tap density.

\subsection{Effect of powder feeding rate on spheroidization}

In the complicated plasma processing, the powder feed rate plays an important role in the spheroidization of molybdenum powders. Under otherwise identical conditions, different feeding rates will lead to different spherical effects. Fig. 5 shows the plasma-processed powder morphologies obtained with different powder feed rates. The percentage of spheroidization with a feeding rate of $50 \mathrm{~g} / \mathrm{min}$ was $98 \%$ but decreased to $90 \%$ for a feeding rate of $70 \mathrm{~g} / \mathrm{min}$; with a feeding rate of $110 \mathrm{~g} / \mathrm{min}$, the spheroidization was only $30 \%$. The reason for this phenomenon might be that with much more powders, a single powder particle can gain very little heat energy under the specific conditions. When the precursor powders were fed into plasma flame at a fixed feed rate of less than $50 \mathrm{~g} / \mathrm{min}$, every single powder particle could gain sufficient heat energy to melt itself completely. However, with a feeding rate greater than $50 \mathrm{~g} / \mathrm{min}$, every single powder particle could not gain this necessary heat energy, resulting in the reduction of the spheroidization efficiency. Yet, too slow of a powder feeding rate also yields a series of shortcomings, such as poor flowability and low apparent density because every single powder particle absorbs too much heat, leading to much smaller molybdenum particles 

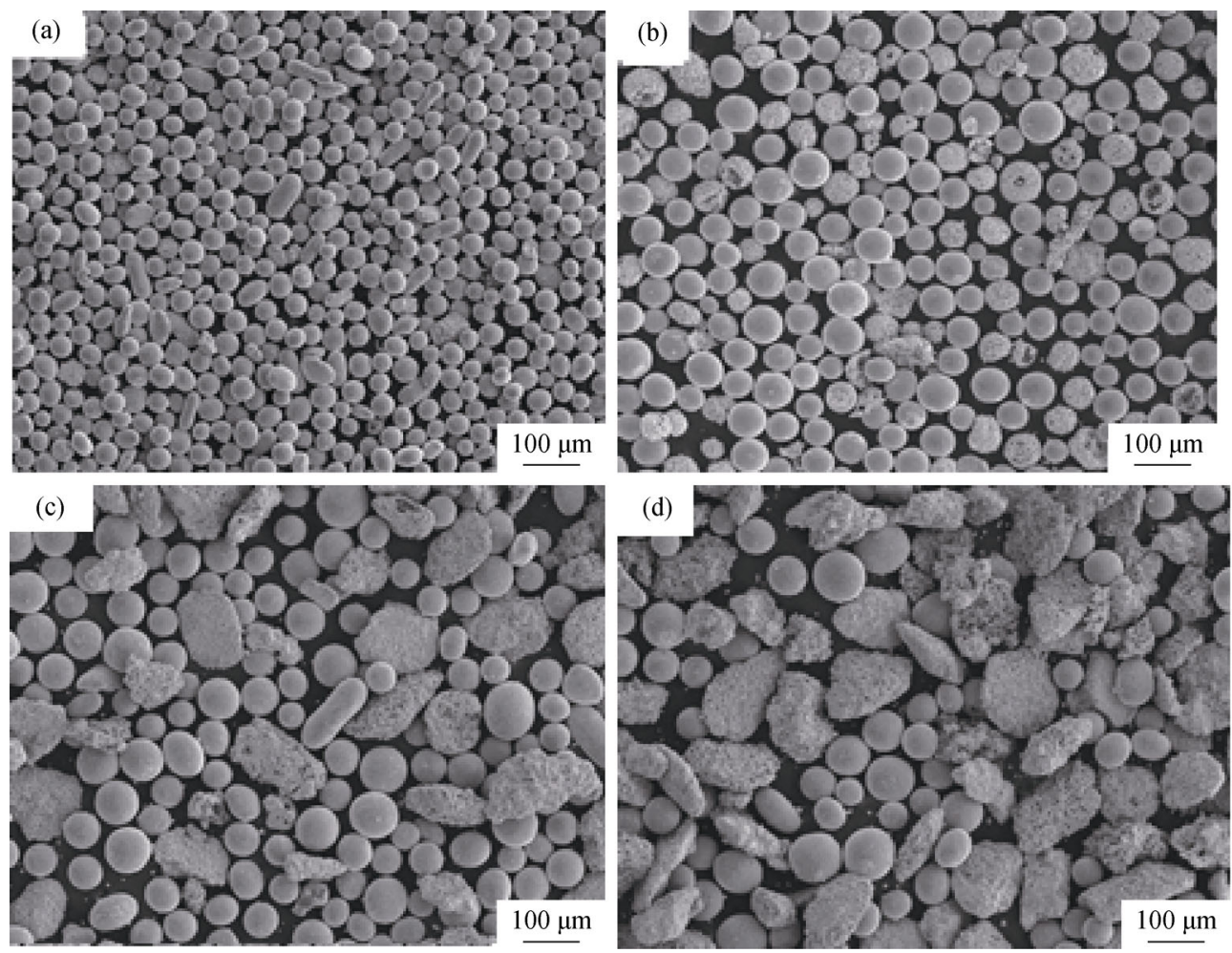

Fig. 5. High-resolution SEM images of Mo products obtained with different powder feeding rates: (a) $50 \mathrm{~g} / \mathrm{min}$, (b) $70 \mathrm{~g} / \mathrm{min}$, (c) 90 $\mathrm{g} / \mathrm{min}$, and (d) $110 \mathrm{~g} / \mathrm{min}$.

and greater surface tension. Therefore, controlling the powder feeding rate is very important to ensure spheroidization efficiency. In the present paper, $50 \mathrm{~g} / \mathrm{min}$ was selected as the optimal powder feeding rate.

\subsection{Spheroidization efficiency effect on the apparent density and flowability}

To evaluate the effect of the spheroidization efficiency on the apparent density and flowability, the apparent density and flowability of the sample in Fig. 5 were measured using a Scott volumeter and Hall flowmeter, respectively. The measurements results are listed in Table 2. Both the apparent density and flowability increased with increasing spheroidization efficiency. After plasma treatment, the raw irregular powders became smooth spherical particles, and the contact area and gap between the particles decreased. Therefore, a higher spheroidization efficiency resulted in improved apparent density and flowability.

Table 2. Apparent density and flowability of plasma-processed molybdenum powder with different spheroidization efficiencies

\begin{tabular}{lcccc}
\hline Spheroidization efficiency / \% & 98 & 90 & 60 & 30 \\
Apparent density / $\left(\mathrm{g} \cdot \mathrm{cm}^{-3}\right)$ & 6.0 & 5.4 & 4.0 & 3.5 \\
Flowability / (s per $50 \mathrm{~g})$ & 11 & 13 & 24 & 32 \\
\hline
\end{tabular}

\subsection{Carrier gas flow rate effect on spheroidization}

Hydrogen in the experiment was used as the carrier gas to inject the raw material of molybdenum powders into the plasma torch. The reducing atmosphere of the hydrogen plasma torch ensured that the molybdenum powders were not oxidized, resulting in high purity. The carrier gas flow rate, together with the amount of time in the plasma torch, affected the molybdenum powder dispersed state. A faster carrier gas flow rate resulted in improved dispersed properties, which would result in higher thermal efficiency of the plasma torch and much higher uniformity of the produced spherical particles. The residence time in the plasma torch was shortened upon increasing the carrier gas flow rate; however, enough heat was required to be absorbed in the plasma torch to melt or vaporize the molybdenum powder. Therefore, too high of a carrier gas flow rate will also affect the quality of spheroidization.

Additionally, introducing hydrogen caused significant changes in the nature of the plasma, such as increasing its thermal conductivity and enthalpy, which ensured that the high-energy plasma also enhanced the energy coupling between the plasma torch and raw powder. Therefore, the hydrogen content in the plasma torch was likely to affect the particle size and morphology of the produced spherical mo- 
lybdenum powder. In the present study, the hydrogen content in the plasma gas was determined by the carrier gas flow rate. Under otherwise identical conditions, different carrier gas flow rates will lead to different spherical effects. Fig. 6 shows the morphologies of the plasma-processed powders obtained with different powder feeding rates. The percentage of spheroidization with the carrier gas flow rate of 0.50 $\mathrm{m}^{3} / \mathrm{h}$ was almost $100 \%$, and the dispersion was decreased compared with Fig. 3(b) $\left(\mathrm{H}_{2} 0.6 \mathrm{~m}^{3} / \mathrm{h}\right)$. The percentage of spheroidization with the feeding rate of $1.0 \mathrm{~m}^{3} / \mathrm{h}$ declined to $60 \%$. There were two reasons for this decrease. First, the velocity of the particles was increased by the higher carrier

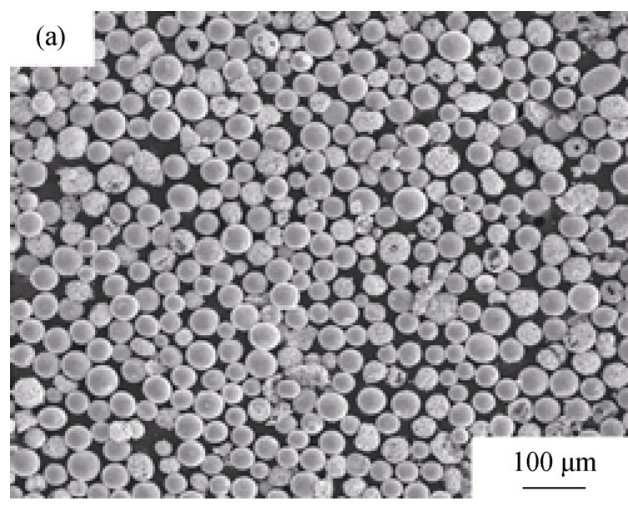

Fig. 6. High-resolution SEM images of the products obtained with different carrier gas flow rates: (a) $0.5 \mathrm{~m}^{3} / \mathrm{h}$ and (b) $1.0 \mathrm{~m}^{3} / \mathrm{h}$.

\section{Conclusions}

(1) Dense spherical molybdenum powder with high purity can be prepared using RF thermal plasma. In addition to spheroidization, RF plasma can purify, densify, and refine the molybdenum powder. Under optimal conditions, the tap density of molybdenum powder was increased from 2.7 to $6.2 \mathrm{~g} / \mathrm{cm}^{3}$.

(2) The effects of the powder feed rate and carrier gas flow rate on the morphology and particle size of the product were systematically investigated. The optimal parameters were $50 \mathrm{~g} / \mathrm{min}$ powder feeding rate and $0.6 \mathrm{~m}^{3} / \mathrm{h}$ carrier gas flow rate.

(3) Because the atmosphere inside the plasma torch is controllable, which is helpful to prepare dense spherical molybdenum powder with high purity, the entire process cycle is short, fast, and shows good potential for industrialization. Therefore, RF plasma is an efficient technique to prepare spherical molybdenum powder with high tap density.

\section{Acknowledgements}

This work was financially supported by the 2012 West-

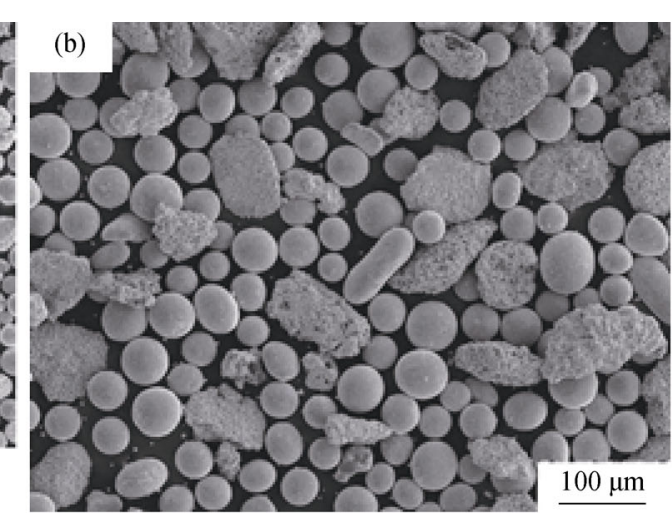

gas flow rate, which would result in more opportunities for the particles to contact and bond with each other; therefore, the number of irregular particles was increased. Second, due to the higher particle velocity, the residence time in the high-temperature area of the plasma was shortened; thus, some molybdenum powder particles did not have enough time to be melted and escaped directly from the high-temperature plasma torch, which caused a low spheroidization efficiency. For the above reasons, it was necessary to select an appropriate carrier gas flow rate during the spherical molybdenum powder preparation. In the present paper, 0.6 $\mathrm{m}^{3} / \mathrm{h}$ was selected as the optimal carrier gas flow rate.

ern Materials Innovation Foundation of China (No. XBCL-1-06), the Science and Technology Coordinating Innovative Engineering Project of Shaanxi Province of China (No. 2014KTCQ01-35), the Natural Science Foundation of Shaanxi Province of China (No. 2014JM6226), and the Specialized Research Fund of Education Commission of Shaanxi Province of China (No. 2013JK0905).

\section{References}

[1] Y.R. Kolobov, B. Kieback, K.V. Ivanov, T. Weissgaerber, N.V. Girsova, Y.I. Pochivalov, G.P. Grabovetskaya, M.B. Ivanov, V.U. Kazyhanov, and I.V. Alexandrov, The structure and microhardness evolution in submicrocrystalline molybdenum processed by severe plastic deformation followed by annealing, Int. J. Refract. Met. Hard Mater., 21(2003), No. 1-2, p. 69.

[2] T. Mrotzek, A. Hoffmann, and U. Martin, Hardening mechanisms and recrystallization behaviour of several molybdenum alloys, Int. J. Refract. Met. Hard Mater., 24(2006), No. 4, p. 298.

[3] Y.W. Sheng, Z.M. Guo, J.J. Hao, H.P. Shao, and Y.M. Wang, Characterization of spherical molybdenum powders prepared by RF plasma processing, Powder Metall. Ind., 21(2011), No. 6, p. 6.

[4] N. Saheb, Spark plasma and microwave sintering of Al6061 
and A12124 alloys, Int. J. Miner. Metall. Mater., 20(2013), No. 2, p. 152.

[5] X. Lu, B. Sun, T.F. Zhao, L.N. Wang, C.C. Liu, and X.H. Qu, Microstructure and mechanical properties of spark plasma sintered Ti-Mo alloys for dental applications, Int. J. Miner. Metall. Mater., 21(2014), No. 5, p. 479.

[6] H. Kersten, D. Rohde, J. Berndt, H. Deutsch, and R. Hippler, Investigations on the energy influx at plasma processes by means of a simple thermal probe, Thin Solid Films, 377-378(2000), p. 585.

[7] M. Belmonte, M.I. Osendi, and P. Miranzo, Modeling the effect of pulsing on the spark plasma sintering of silicon nitride materials, Scripta Mater., 65(2011), No. 3, p. 273.

[8] Y.H. Chang, D. Huang, C.C. Jia, Z.W. Cui, C.C. Wang, and D. Liang, Influence of plasma on the densification mechanism of SPS under multi-field effect, Int. J. Miner. Metall. Mater., 21(2014), No. 9, p. 906.

[9] H.P. Zhou, S. Xu, Z. Zhao, and Y. Xiang, Inductively coupled hydrogen plasma processing of AZO thin films for heterojunction solar cell applications, J. Alloys Compd., 610(2014), p. 107.

[10] B.H. Liu, H.C. Gu, and Q.L. Chen, Preparation of nanosized Mo powder by microwave plasma chemical vapor deposition method, Mater. Chem. Phys., 59(1999), No. 3, p. 204.

[11] Y.M. Wang, J.J. Hao, and Y.W. Sheng, Spheroidization of Nd-Fe-B Powders by RF Induction Plasma Processing, Rare. Met. Mater. Eng., 42(2013), No. 9, p. 1810.

[12] T. Ryu, H.Y. Sohn, Y.U. Kim, and M. Olivas-Martinez, Plasma synthesis of nanosized W-Co composite powder followed by carburization with a methane-hydrogen mixture, $J$. Nanopart. Res., 12(2010), No. 8, p. 2851.

[13] J.L.H. Chau, Synthesis of Ni and bimetallic FeNi nanopowders by microwave plasma method, Mater. Lett., 61(2007), p. 2753.

[14] O. Fukumasa, Synthesis of new ceramics from powder mix- tures using thermal plasma processing, Thin Solid Films, 390(2001), No. 1-2, p. 37.

[15] Y.W. Sheng, Z.M. Guo, J.J. Hao, H.P. Shao, and S.C. Wang, Preparation of micro-spherical titanium powder by RF plasma, Rare. Met. Mater. Eng., 42(2013), No. 6, p. 1291.

[16] H.B. Zhang, L.Y. Bai, P. Hu, F.L. Yuan, and J.L. Li, Single-step pathway for the synthesis of tungsten nanosized powders by RF induction thermal plasma, Int. J. Refract. Met. Hard. Mater., 31(2012), p. 33.

[17] L.Y. Bai, J.M. Fan, P. Hu, F.L. Yuan, J.L. Li, and Q. Tang, $\mathrm{RF}$ plasma synthesis of nickel nanopowders via hydrogen reduction of nickel hydroxide/carbonate, J. Alloys Compd., 481(2009), No. 1-2, p. 563.

[18] P. Hu, S.K. Yan, F.L. Yuan, L.Y. Bai, J.L. Li, and Y.F. Chen, Effect of plasma spheroidization process on the microstructure and crystallographic phases of silica, alumina and nickel particles, Plasma Sci. Technol., 9(2007), No. 5, p. 611.

[19] T. Ryu, H.Y. Sohn, K.S. Hwang, and Z.Z. Fang, Chemical vapor synthesis (CVS) of tungsten nanopowder in a thermal plasma reactor, Int. J. Refract. Met. Hard. Mater., 27(2009), No. 1, p. 149.

[20] M. Boulos, Plasma power can make better powders, Met. Powder Rep., 59(2004), No. 5, p. 16.

[21] T.S. Ko, S. Yang, H.C. Hsu, C.P. Chu, H.F. Lin, S.C. Liao, T.C. Lu, H.C. Kuo, W.F. Hsieh, and S.C. Wang, ZnO nanopowders fabricated by dc thermal plasma synthesis, $M a$ ter. Sci. Eng. B, 134(2006), No. 1, p. 54.

[22] S. Kumar, V. Selvarajan, P.V.A. Padmanabhan, and K.P. Sreekumar, Spheroidization of metal and ceramic powders in thermal plasma jet: comparison between experimental results and theoretical estimation, J. Mater. Process. Technol., 176(2006), No. 1-3, p. 87.

[23] X.L. Jiang and M. Boulos, Induction plasma spheroidization of tungsten and molybdenum powders, Trans. Nonferrous Met. Soc. China, 16(2006), No. 1, p. 13. 